\title{
Response Characteristics of Flame Thermionic Detector to Sulfur Compounds
}

\author{
Hiromi ARImoto*, Kaori Ozaki*, Koichi ShIomi* and Naoki HaMadA** \\ *Kyoto Analytical Applications Center, Shimadzu Corp., Nishinokyokuwabaracho, Kyoto 604, Japan \\ **Tokyo Analytical Applications Center, Shimadzu Corp., Shibasaki 1-chome, Chofu, Tokyo 182, Japan
}

\begin{abstract}
The response characteristics of flame thermionic detectors (FTDs) to sulfur compounds were studied. The optimum flow rates of air and hydrogen were obtained by investigating changes in the detector response and selectivity for hydrocarbons with respect to changes in the air and hydrogen flow rates. From these investigations, the response for sulfur compounds shows a high sensitivity at an air flow rate of about $6 \mathrm{ml} \mathrm{min}$, as well as $100 \mathrm{ml} \mathrm{min}^{-1}$ or $16 \mathrm{ml} \mathrm{min}^{-1}$. Investigations were carried out concerning the detection limit, response linearity and selectivity for representative sulfur compounds (under these set of operational conditions). Disulfides were detected at especially high sensitivity, under $16 \mathrm{ml} \mathrm{min}^{-1}$ air flow rate conditions. The detection limit of dimethyl disulfides was $1.78 \times 10^{-10} \mathrm{~g} \mathrm{~s}^{-1}(S /$ $N=2$ ), and the selectivity for hydrocarbons was $1.7 \times 10^{3} \mathrm{gC} / \mathrm{gS}$. Exact details concerning the negative surface ionization process on alkali metal surface are not completely known. The presumed ionization process for organic sulfur compounds is discussed in this paper.
\end{abstract}

Keywords Flame thermionic detector, sulfur compounds, negative surface ionization, gas chromatography

Flame thermionic detectors (FTDs) characteristically display highly selective and sensitive response to nitrogen, phosphorus and halogen compounds. ${ }^{1-5}$ However, reported applications have been limited to nitrogen and phosphorus compounds. We were interested in whether the FTD's high selectivity could be extended to sulfur compounds. FPD (flame photometric detector) has been widely adopted for highly sensitive detection of sulfur compounds up to the present. ${ }^{6-8}$ However, the response of FPD for sulfur compounds was not linear and gave low selectivity.

Our investigations showed that FTDs have a fairly high selectivity for sulfur compounds, though not as high as that for nitrogen or phosphorus compounds; under certain conditions, however, high sensitivity to particular types of sulfur compounds can be achieved.

\section{Experimental}

\section{Apparatus}

The gas chromatograph (GC) system was assembled from a GC-14A equipped with an FTD-14 flame thermionic detector (both Shimadzu Corp., Kyoto, Japan). Figure 1 is a cross-section of the FTD-14. A rubidium sulfate $\left(\mathrm{Rb}_{2} \mathrm{SO}_{4}\right)$ bead is sintered to a platinum wire and used as an alkali metal source. The bead is positioned above the effluent jet and is centered in the cylindrical outer collector just below an inner collector, which also serves as the exhaust pipe. The $\mathrm{Pt}$ wire on which the bead is bonded bridges the coaxial collectors which are physically and electrically isolated by a ceramic filler. A power controller regulates the current in the collectorbead-collector loop to provide bead temperature control $\left(600 \sim 800^{\circ} \mathrm{C}\right)$ and overcurrent protection, while an electrometer tap on the inner collector serves to monitor

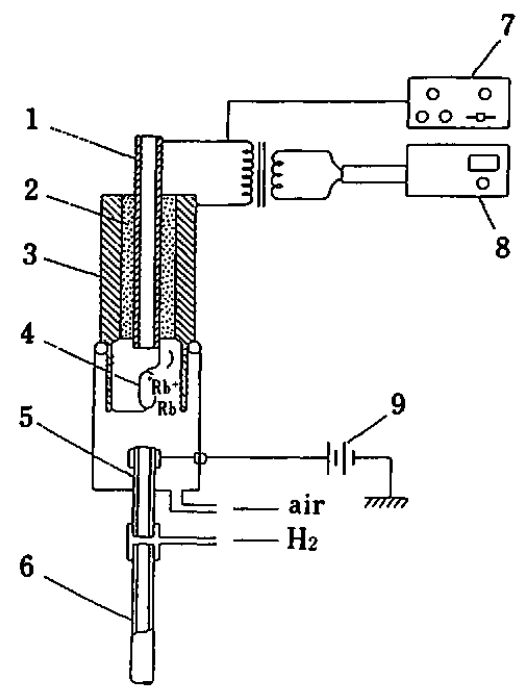

Fig. 1 Cross-section of the FTD cell used in the experiments (FTD-14): 1, inner collector; 2, ceramic insulator; 3, outer collector; 4, rubidium bead; 5 , quartz jet; 6 , column; 7 , electrometer; 8 , power controller; 9 , high voltage supply. 
the ion current. A high-voltage DC source impresses a potential of $c a .200 \mathrm{~V}$ across the metallic tip of the quartz jet and the collector assembly. The column effluent is mixed with hydrogen before exiting the jet, while air is supplied around the base of the jet. The mixture is burnt in a high-entropy plasma which envelops the bead. The FTD-14 fits easily into the existing FID (flame ionization detector) position of the GC-14A; the only modification required is an addition of flow restriction to the FID flow controller, since the FTD-14 uses relatively low flow rates for air and $\mathrm{H}_{2}$.

The column was a polyphenylether (5 ring), $10 \%$ on Shimalite TPA (60 - $80 \mathrm{mesh}), 3 \mathrm{~m} l \times 3 \mathrm{~mm}$ i.d., glass column.

The carrier gas was helium delivered at $44 \mathrm{ml} \mathrm{min}^{-1}$, with a column temperature of $100^{\circ} \mathrm{C}$, and an injection port/detector temperatures of $250^{\circ} \mathrm{C}$.

All of the reagents were of analytical grade. Methyl mercaptan, methyl sulfide, thiophene, dimethyl disulfide, dibutyl disulfide, diphenyl disulfide, 2-methyl thiophene, and 3-methyl thiophene as representative sulfur compounds, and decane, as a typical hydrocarbon, were obtained from Wako Pure Chemical Industries Ltd.

\section{Results and Discussion}

Relationship between the detector response to sulfur compounds, and different hydrogen flow rates and air flow rates

In order to find the optimum hydrogen and air flow rates for the determination of sulfur compounds, detector responses and selectivities were obtained under different hydrogen and air flow rate conditions.

The sample was an acetone solution containing $10^{3} \mu \mathrm{g} \mathrm{ml}^{-1}$ each of thiophene and dimethyl disulfides as sulfur compounds and $10^{4} \mu \mathrm{g} \mathrm{ml}^{-1}$ of decane as the hydrocarbon.

Figure 2 shows how the detector response to these

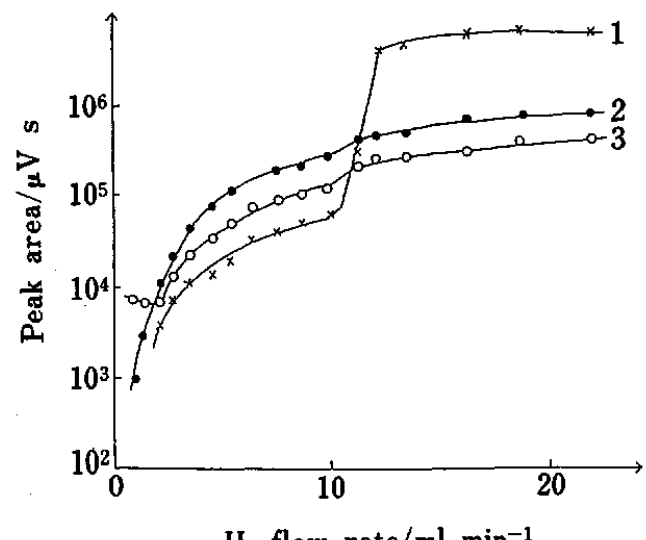

Fig. 2 Relationship between the response to sulfur compounds and decane, and the hydrogen flow rate: 1 , decane $\left(10^{4} \mu \mathrm{g} \mathrm{ml}^{-1}\right) ; 2$, thiophene $\left(10^{3} \mu \mathrm{g} \mathrm{ml}^{-1}\right) ; 3$, dimethyl disulfide $\left(10^{3} \mu \mathrm{g} \mathrm{ml}^{-1}\right)$. three compounds varies with a change in the hydrogen flow rate, the air flow rate being kept constant at $102 \mathrm{ml} \mathrm{min}^{-1}$. The detector response to sulfur compounds increased with an increase in the hydrogen flow rate and was almost constant above $11 \mathrm{ml} \mathrm{min}{ }^{-1}$. The detector response to decane also increased with an increase in the hydrogen flow rate, making a sharp increase around $11 \mathrm{ml} \mathrm{min}-1$; it is relatively constant above this point.

Figure 3 shows how the selectivities for thiophene and methyl disulfide against decane vary with a change in the hydrogen flow rate. The data shown in Fig. 3 were calculated from the data used in Fig. 2. The selectivity is defined as the ratio between the mass sensitivity to sulfur compounds and decane. The selectivity for thiophene is maximized at about $6.5 \mathrm{ml} \mathrm{min}^{-1}$ of the hydrogen flow rate; that for dimethyl disulfide is maximized at about $5.5 \mathrm{ml} \mathrm{min} \mathrm{m}^{-1}$. When the hydrogen flow rate is increased above these points, the selectivities for thiophene and dimethyl disulfide decrease. When the hydrogen flow rate is increased to $11 \mathrm{ml} \mathrm{min}^{-1}$, which gives the highest sensitivity for decane, no significant increase in the selectivity is obtained for thiophene and methyl disulfide. Figures 2 and 3 show that the optimum hydrogen flow rate is about $5.5 \mathrm{ml} \mathrm{min}^{-1}$.

Next, the optimum air flow rate was obtained. Figure 4 shows how the detector responses to thiophene, methyl disulfide, and decane vary with changes in the air flow rate, the hydrogen flow rate being kept at $5.5 \mathrm{ml} \mathrm{min}^{-1}$, as determined above.

The detector response to the sulfur compounds increased with the air flow rate and became maximized at about $120 \mathrm{ml} \mathrm{min} \mathrm{m}^{-1}$; it gradually decreased if the air flow rate was increased to above $120 \mathrm{ml} \mathrm{min}^{-1}$. Decane gives a similar response curve, though with a somewhat different slope. It is noteworthy that when the air flow rate is decreased to below $30 \mathrm{ml} \mathrm{min}^{-1}$, thiophene and decane are hardly detectable; also, the detector sensitivity

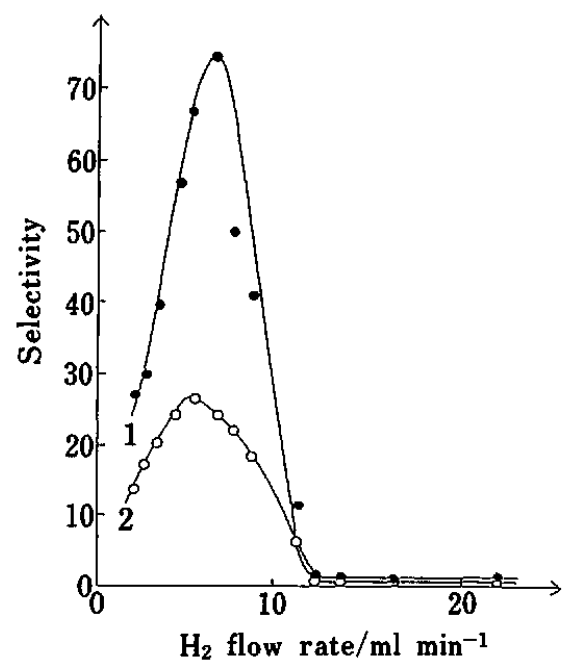

Fig. 3 Selectivity for sulfur compounds $v s$, the hydrogen flow rate. The selectivity is mass sensitivity relative to decane: 1 , thiophene; 2, dimethyl disulfide. 
Table 1 FTD response to sulfur compounds

\begin{tabular}{|c|c|c|c|c|}
\hline Sulfur compound & Structural formula & Selectivity $^{\mathbf{a}}$ & Slope $^{b}$ & Minimum detectable quantity $/ \mathrm{g} \mathrm{s}^{-1}$ \\
\hline Methyl mercaptan & $\mathbf{R}-\mathrm{S}-\mathrm{H}$ & 9.14 & 0.76 & $5.25 \times 10^{-11}$ \\
\hline Dimethyl sulfide & $\mathbf{R}-\mathbf{S}-\mathbf{R}$ & 20.13 & 0.61 & $2.13 \times 10^{-11}$ \\
\hline Carbon disulfide & $\mathrm{S}=\mathrm{C}=\mathrm{S}$ & 20.62 & 0.59 & $9.47 \times 10^{-12}$ \\
\hline Thiophene & & 24.68 & 0.83 & $1.84 \times 10^{-10}$ \\
\hline Dimethyl disulfide & $\mathbf{R}-\mathbf{S}-\mathbf{S}-\mathbf{R}$ & 12.30 & 0.71 & $1.05 \times 10^{-10}$ \\
\hline
\end{tabular}

a. Selectivity is defined as the ratio between mass sensitivity to sulfur compounds and decane. $b$. Slope is slope of the curves in the linear response range $\mathrm{R}-=\mathrm{CH}_{3}-$.

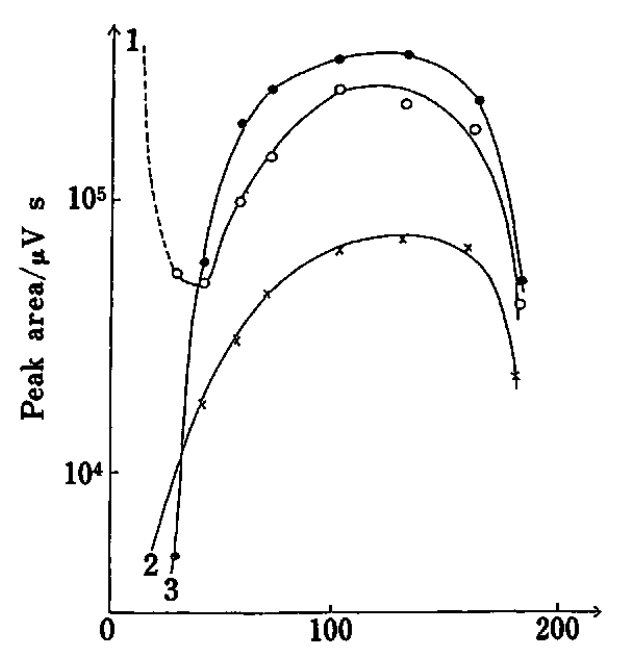

Air flow rate/ml min-1

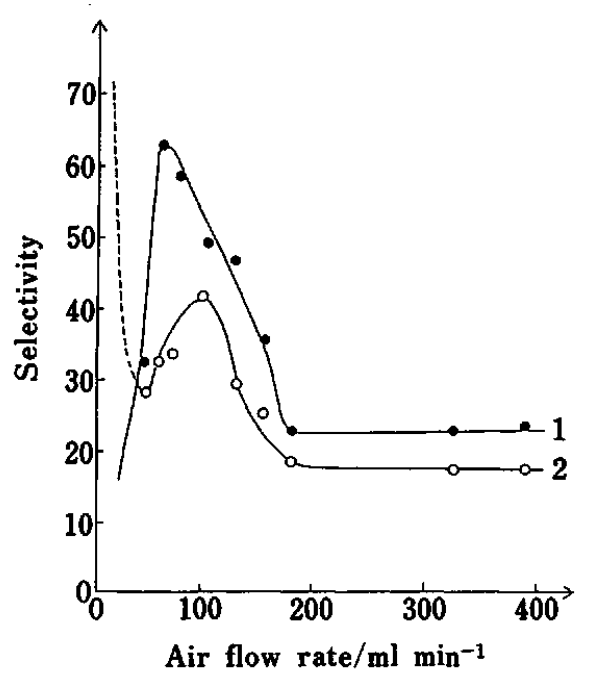

Fig. 5 Selectivity for sulfur compounds $v s$. the air flow rate. The selectivity is mass sensitivity relative to decane. 1 , thiophene; 2, dimethyl disulfide.

structures into five groups, and the representative compound of each group was determined. Table 1 gives the names, chemical structures, selectivities, and slopes of the curves in the linear response range, as well as the detection limits for these compounds.

\section{Selectivity}

All of the sulfur compounds are detected with sensitivities of only 10- to 20-times higher than that for decane. The sensitivities are not sufficiently selective.

\section{Detection limit}

The detection limits for these sulfur compounds are $10^{-10}-10^{-12} \mathrm{~g} \mathrm{~s}^{-1}$, which correspond to $0.50 \mathrm{ng}$ of methyl mercaptan, $0.18 \mathrm{ng}$ of dimethyl sulfide, $0.07 \mathrm{ng}$ of carbon disulfide, $2.2 \mathrm{ng}$ of thiophene, and $2.1 \mathrm{ng}$ of dimethyl disulfide. Figure 6 shows, as an example, a chromatogram of $1.0 \mathrm{ng}$ carbon disulfide. This chromatogram shows that the detection limit of carbon disulfide is below the $10^{-10} \mathrm{~g}$ quantity level.

\section{Linearity}

The measurement of the linear range has been made 


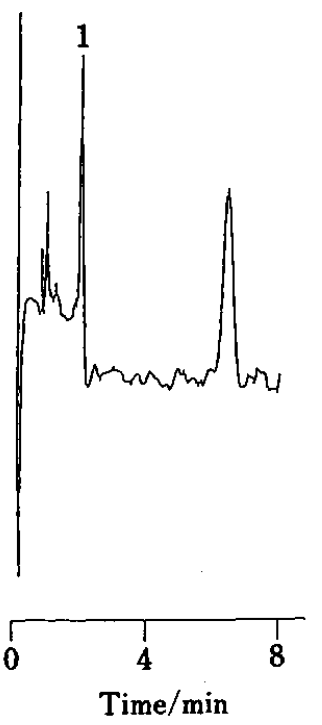

Fig. 6 Gas chromatogram showing the minimum detectable quantity for $\mathrm{CS}_{2}\left(1 \times 10^{-9} \mathrm{~g}\right.$ injected $)$. Sensitivity, $2 \times 10^{-11} \mathrm{~A}$ full scale; (1) CS2 $1 \times 10^{-9} \mathrm{~g}$.

with sulfur compounds in Table 1 as a test sample, showing that the straight portion of the working curves covers nearly 4 orders of magnitude for the sulfur compounds. The slopes of the working curves for sulfur compounds are shown in Table 1.

Characteristics of the response to sulfur compounds with a $16 \mathrm{ml} \mathrm{min}^{-1}$ air flow rate

In a study of the air flow rate dependency of the detector response to sulfur compounds, it was found that dimethyl disulfide is detected with high selectivity when the air flow rate is reduced to below $30 \mathrm{ml} \mathrm{min}^{-1}$. A detailed investigation was carried out concerning this finding.

Figure 7 shows chromatograms of sulfur compounds obtained with the air flow rate set at $100 \mathrm{ml} \mathrm{min}^{-1}$ (optimum flow rate) and $16 \mathrm{ml} \mathrm{min}^{-1}$. The sample was $1 \%$ decane solution of thiophene, dimethyl disulfide, 2methyl thiophene, and 3-methyl thiophene. When the air flow rate was set to $16 \mathrm{ml} \mathrm{min}^{-1}$, only dimethyl disulfide was detected; the other sulfur compounds and decane were not detected at all. An air flow rate of $16 \mathrm{ml} \mathrm{min}-1$ gives a more stable base line than at $100 \mathrm{ml}$ $\mathrm{min}^{-1}$. A further investigation was carried out in order to see if other disulfides have the same tendency. The sample was $1 \%$ decane solution of dimethyl sulfide, thiophene, dimethyl disulfide, and dibutyl disulfide. Figure 8 shows chromatograms of this sample obtained with the air flow rate set at $16 \mathrm{ml} \mathrm{min}^{-1}$ and $100 \mathrm{ml} \mathrm{min}^{-1}$ (optimum flow rate). The glass column was $\mathrm{OV}-17,2 \%$ on Chromosorb W (AW, DMCS treated), with a length of $1 \mathrm{~m}$ and an inner diameter of $3 \mathrm{~mm}$. The column temperature was $100^{\circ} \mathrm{C}$.

When the air flow rate was set at $16 \mathrm{ml} \mathrm{min}^{-1}$, only dimethyl disulfide and dibutyl disulfide were detected; the other sulfur compounds and decane were not detected

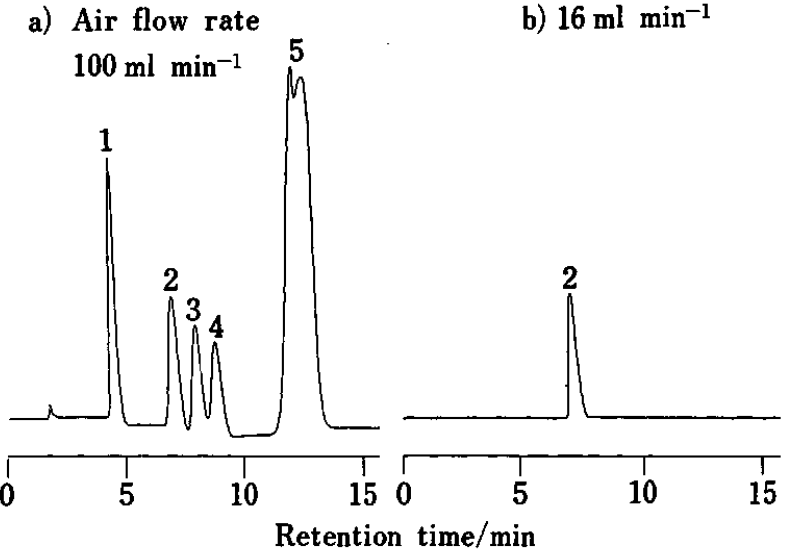

Fig. 7 Gas chromatograms of sulfur compounds obtained with the air flow rate set at $100 \mathrm{ml} \mathrm{min}^{-1}$ and $16 \mathrm{ml} \mathrm{min}^{-1}$. Column; 10\% PPE (5 ring) on Shimalite TPA, 60 - 80 mesh, $3 \mathrm{~m} \times 3.0 \mathrm{~mm}$ i.d. Temperature, column $100^{\circ} \mathrm{C}$, injection port/detector $250^{\circ} \mathrm{C}$; hydrogen flow rate $6.0 \mathrm{ml} \mathrm{min}^{-1}$; sensitivity, $3.2 \times 10^{-10} \mathrm{~A}$ full scale. (1) thiophene; (2) dimethyl disulfide; (3) 2-methyl thiophene; (4) 3-methyl thiophene; (5) decane.

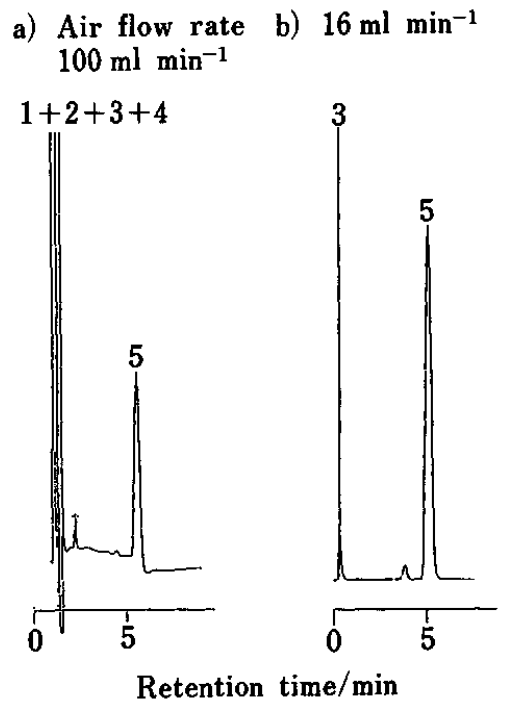

Fig. 8 Gas chromatograms of sulfur compounds obtained with the air flow rate set at $16 \mathrm{ml} \mathrm{min}^{-1}$ and $100 \mathrm{ml} \mathrm{min}^{-1}$. Column: $2 \%$ OV-17 on Chromosorb W (AW, DMCS treated), $80-100$ mesh, $1 \mathrm{~m} \times 3 \mathrm{~mm}$ i.d., glass column; temperature, column $100^{\circ} \mathrm{C}$, injection port/detector $250^{\circ} \mathrm{C}$; hydrogen flow rate $6 \mathrm{ml} \mathrm{min}{ }^{-1}$; carrier gas $\mathrm{He} 40 \mathrm{ml} \mathrm{min}^{-1}$; sensitivity $3.2 \times 10^{-10} \mathrm{~A}$ full scale. (1) dimethyl sulfide; (2) thiophene; (3) dimethyl disulfide; (4) decane; (5) dibutyl disulfide.

at all. Another experiment showed that diphenyl disulfide has the same tendency. The above-mentioned experiments show that when the air flow rate is set at $16 \mathrm{ml} \mathrm{min}^{-1}$, disulfides are detected with far higher sensitivity than other sulfur compounds. Under this set of operational conditions, disulfides are detected with about $10^{3}$ times higher sensitivity compared with hydrocarbonds. It is also noteworthy that the $16 \mathrm{ml}$ 
$\min ^{-1}$ air flow rate provides a far more stable base line, compared with that at a $100 \mathrm{ml} \mathrm{min}^{-1}$ air flow rate.

Our conclusion is that this set of operational conditions (when air flow rate is set at $16 \mathrm{ml} \mathrm{min}{ }^{-1}$ ) provides excellent efficiency in the analysis of disulfides. The disulfides analyzed were dimethyl disulfide, dibutyl disulfide and diphenyl disulfide. The response curve for dimethyl disulfide has a slope of 0.71 when the air flow rate is set at $100 \mathrm{ml} \mathrm{min}-1$, and 1.45 when it is set at $16 \mathrm{ml} \mathrm{min}^{-1}$. The linear dynamic range for dimethyl disulfide is as wide as $10^{3}$. The selectivity for dimethyl disulfide is 1745 against decane, and the minimum detectable amount is $1.78 \times 10^{-10} \mathrm{~g} \mathrm{~s}^{-1}$ (at $S / N=2$ ). The optimum set of operational conditions was confirmed by measuring the detector response for different hydrogen flow rates; the detector response was highest when the hydrogen flow rate was set at $5.5 \mathrm{ml} \mathrm{min}^{-1}$.

\section{Negative surface ionization on alkali metal salt surface}

Exact details concerning the negative surface ionization process 9 on an alkali metal surface are not completely known. The following outlines the presumed ionization process for organic sulfur compounds. Effluents from the column are forced up against the alkali metal salt bead under the influence of the carrier gas pressure. The salt bead, which is a rubidium sulfate coating on a platimum wire, is heated $600-800^{\circ} \mathrm{C}$ by a current supplied from the power controller and detector cell transformer mechanism. The high temperature of the alkali bead and surrounding hydrogen plasma causes a thermal fragmentation of organic sulfur compounds liberating radicals containing sulfur. The high-entropy plasma state around the alkali bead is also supported by the high bead temperature; thus, numerous collisions occur. Through these collisions, the sulfur radicals gain electrons and become negative ions; rubidium atoms become positive ions.

From these data it is assumed that an air flow rate of $100 \mathrm{ml} \mathrm{min}^{-1}$ results in an extensive oxidation of the sulfur of $\mathrm{SO}_{x}$ species, which collide with the excited rubidium atoms, giving rise to $\mathrm{SO}_{x}^{-}$, as shown in Eq. (1); in this case, the detection of ionic oxides predominates,

$$
\mathrm{Rb}^{*}+\mathrm{SO}_{x} \rightarrow \mathrm{Rb}^{+}+\mathrm{SO}_{x}^{-}
$$

With an air flow rate of $16 \mathrm{ml} \mathrm{min}^{-1}$ the predominating mechanism is the formation of simple sulfide from the disulfide, and subsequent ionization (Eq. (2)) and detection

$$
2 \mathrm{Rb}^{*}+\mathrm{RS}-\mathrm{RS} \rightarrow 2 \mathrm{Rb}^{+}+2 \mathrm{R}-\mathrm{S}^{-} .
$$

\section{References}

1. J. Sevick, Chromatographia, 6, 139 (1973).

2. V. V. Brazhnikov, M. V. Gurev and K. I. Sakodynsky, Chromatogr. Rev., 12, 1 (1970).

3. W. A. Aue, G. W. Gehrke, R. C. Tindle, D. L. Stalling and C. D. Rugle, J. Gas Chromatogr., 5, 381 (1967).

4. P. L. Patterson and R. L. Howe, J. Chromatogr. Sci., 16, 275 (1975).

5. P. L. Patterson, J. Chromatogr. Sci., 24, 41 (1986).

6. A. Attar, R. Forgey, J. Horn and W. H. Corcoran, J. Chromatogr. Sci., 15, 222 (1977).

7. C. H. Burnett, D. F. Adams and S. O. Farwell, J. Chromatogr. Sci., 15, 230 (1977).

8. C. D. Pearson and W. J. Hines, Anal. Chem., 49, 123 (1977).

9. T. Fujii and H. Arimoto, Anal. Chem., 57, 490 (1985).

(Received October 23, 1991)

(Accepted January 16, 1992) 